\title{
Erbium Laser-assisted Closed-flap Crown Lengthening: A Review of the Literature
}

\author{
${ }^{1}$ Urmi Bhattacharyya, ${ }^{2}$ Anisha Shah, ${ }^{3}$ Suchetan Pradhan
}

\begin{abstract}
Crown lengthening is a preprosthetic surgical procedure that results in the exposure of more tooth structure and reestablishment of a more apical gingival margin. Traditionally, it is an open-flap surgical procedure. Smile designing is becoming an increasingly popular treatment option, and the use of lasers for a crown lengthening greatly enhances the patient acceptability while reducing chairside time. There are no controlled studies for this application of lasers, however, a number of clinical case reports do exist. This article mainly focuses on reviewing all the current literature on crown lengthening performed by erbium lasers and exploring the process to achieve the best results.
\end{abstract}

Keywords: Closed-flap, Crown lengthening, Dental laser application, Erbium lasers.

How to cite this article: Bhattacharyya U, Shah A, Pradhan S. Erbium Laser-assisted Closed-flap Crown Lengthening: A Review of the Literature. Int J Laser Dent 2015;5(3):63-67.

Source of support: Nil

Conflict of interest: None

\section{INTRODUCTION}

Crown lengthening is a preprosthetic surgical procedure that results in the exposure of more tooth structure and reestablishment of a more apical gingival margin. It is often required to enhance the retention of a fixed prosthesis or a dental restoration and prevent violation of the biologic width. ${ }^{1-3}$ With the development of esthetic dentistry and the concept of "smile designing," it is now commonly used to enhance the appearance of a patient's smile., ${ }^{1,-6}$ This paper mainly focuses on highlighting an alternative approach to crown lengthening in the esthetic zone.

A traditional crown-lengthening procedure involves an open-flap surgery and removal of bone with rotary instruments. ${ }^{1,2,7,8}$ The healing period for such a procedure is usually 4 to 6 weeks. ${ }^{1,7,8}$ It may lead to postsurgical complications, such as excessive bleeding, infection, repositioning of the marginal gingiva, and inflammation. ${ }^{7,9,10}$

\footnotetext{
${ }^{1,2}$ Dentist, ${ }^{3} \mathrm{Head}$

${ }^{1}$ Department of Education, Pradhan Dental Centre, Mumbai Maharashtra, India

${ }^{2,3}$ Department of Clinical, Pradhan Dental Centre, Mumbai Maharashtra, India

Corresponding Author: Urmi Bhattacharyya, Dentist Department of Education, Pradhan Dental Centre, Mumbai Maharashtra, India, Phone: +912267991111, e-mail: urmi. bhattacharyya23@gmail.com
}

Erbium lasers offer an alternative which is minimally invasive and eliminate most of the complications faced in a conventional procedure. ${ }^{2}$ Healing time is also significantly reduced. ${ }^{1}$

\section{WORKING OF ERBIUM LASERS}

Erbium lasers are considered both hard- and soft-tissue lasers in dentistry. They are available in two wavelengths: Er:YAG (Erbium:Yatrium-Aluminium-Garnet, $2.94 \mu \mathrm{m}$ ) and Er,Cr:YSGG (Erbium, Chromium:Yttrium-SeleniumGallium-Garnet, $2.78 \mu \mathrm{m}) .{ }^{11,12}$ These mid-infrared wavelengths are highly absorbed primarily by water and also by hydroxyapatite and remove tissue by thermomechanical ablation. ${ }^{1,13,14}$ The wavelengths are absorbed on the surface of the targeted tissue. Irradiating hard tissue with erbium lasers leads to rapid subsurface expansion of the interstitially trapped water within the mineral substrate causing a massive volume expansion which leads to microexplosions in the surrounding tissues. A water coolant and short pulse duration minimizes the heat transfer to the tooth. ${ }^{15-17}$ By adjusting the power density, the erbium lasers can be used to create similar microexplosions in soft tissue. This causes a "shaving" or "planing" of the soft tissue rather than the deeper absorbed action of dedicated soft-tissue lasers. ${ }^{15,18}$ They are emitted via a free-running pulsed mode, and an accompanying water and air spray disperses debris and cools the operating field. Hence, the lasers ablate hard and soft tissue atraumatically when compared with removal via rotary instruments. ${ }^{1,19-21}$

A study conducted by Kimura et al, ${ }^{22}$ which evaluated the morphological and temperature changes in canine mandibular bone, in vitro, irradiated by Er,Cr:YSGG laser, found no changes in the calcium/phosphate ratio (EDX analysis) and no evidence of charring or melting. ${ }^{12}$ Tosun et $\mathrm{al}^{1}$ conducted an in vitro study on sheep mandible comparing osseous recontouring via Er:YAG laser and conventional rotary instruments and found that macroscopically both methods had the same effect on bone topography. Microscopically, the Er:YAG laser was shown to create rougher surfaces on bone. However, Tosun Tosun concludes that the outcome of a crown-lengthening procedure depends on the contouring of the crestal bone and the maintenance of biologic width and hence, the increased microscopic roughness is not significant. 


\section{WHY USE ERBIUM LASERS?}

Crown lengthening is used to correct a number of esthetic problems, such as "a gummy smile" and disproportionate appearance of gingiva, especially in the anterior zone. ${ }^{2,15,23,24}$ Since cosmetic dentistry majorly deals with the anterior teeth, a minimally invasive procedure and a reduced healing time greatly benefits the patient. ${ }^{2,24} \mathrm{~A}$ closed-flap approach using lasers excludes the need for reflecting a flap, which in turn reduces the possibility of swelling and eliminates the need for sutures. Tension in the tissue due to suturing often leads to irregular tissue positioning postoperatively. ${ }^{2}$ Following a traditional crown-lengthening surgery, there is up to a 6-month period of considerable tissue instability or "rebound" as concluded in a study by Deas et al. ${ }^{2,8}$ Pontoriero et al also concluded that marginal tissue has a tendency of growing coronally after an apically positioned flap and osseous resection. ${ }^{2,7}$ Bragger et $\mathrm{al}^{25}$ reported gingival recession between 6 weeks and 6 months in 12\% of cases after a conventional crown lengthening. This might necessitate a revision surgery to establish the desired margins. ${ }^{2} \mathrm{~A}$ closed-flap technique ensures more stable margins ${ }^{7}$ and minimizes the need for a revision surgery in most cases.

The hemostatic properties of lasers increase the visibility, the biostimulation effect enhances postoperative healing, and the postoperative margins are more likely to remain stable. The procedure is also relatively pain-free and requires minimal chair time..$^{2,24}$

$\mathrm{Cobb}^{11}$ raises a number of questions in his literature review of lasers in periodontology.

Is there sufficient tactile sensation transmitted through the laser delivery tip to allow the clinician to adequately distinguish between bone and root surface cementum and/or dentin?"11 Various clinicians recommend keeping the laser tip as parallel to the root surface as possible and following the gingival contour while resecting bone to minimize damage to the tooth surface. ${ }^{2,15,23,24}$

Have any of these reports determined if the roots of treated teeth incur surface damage, e.g., catering, ditching, charring, heat-induced cracking, or melting?"11 Yung ${ }^{26}$ conducted an uncontrolled study on 60 patients in a private setting with erbium lasers for various surgical periodontal procedures. The patients were followed up for 1 week, 1, 3 months, and up to 4 years later. He observed that even in a confined surgical site, such as in a closed-flap crown lengthening, if the intention and direction of the laser application is carefully preplanned, selective ablations can be successfully performed.

In cases requiring bone removal, does the lack of direct visualization allow the clinician to establish proper anatomical dimensions and contours that will maintain the gingival papilla postsurgically and prevent violation of the biologic width?"11 Most clinicians mark the desired depth of resection onto the laser tip with the help of a caliper before the resection. 2,15,23,24 Bone is resected following the natural anatomical contours of the tooth. 2,15,23,24 Dyer recommends a sweeping motion from the mesial to the distal. ${ }^{8}$ Flax uses a "sewing machine stitch" motion (precise up and down movements) for his clinical cases. ${ }^{15}$

However, there are no controlled longitudinal or cohort studies supporting use of lasers for clinical crown lengthening using the closed-flap technique. There are no published research data. ${ }^{11}$

\section{Steps for the Procedure}

\section{Case Selection}

Appropriate case selection is essential to achieve maximum benefits of this treatment approach. ${ }^{24,27}$ The teeth in question should be of sound periodontal health. A comprehensive evaluation should be performed before deciding the method of treatment in each case (Fig. 1). Preoperative records should include:

- Full mouth radiographs

- Diagnostic casts and casts with wax mock-ups if necessary

- "Diagnostic digital photographs recording the width and length of the anterior teeth, midline, gingival symmetry, and the position of the free gingivae in relation to the position of the upper lip during smiling ${ }^{2 \prime \prime}$

- "Diagrammatic depictions of the level of gingiva to be achieved postoperatively on all photographic records" ${ }^{2 \prime}$

- "A complete intraoral examination to assess the periodontal health of all teeth present, which should include assessment of crown-root ratios, probing depth, bleeding on probing, plaque and gingival indices, tooth mobility, and bone loss. ${ }^{2 \prime \prime}$

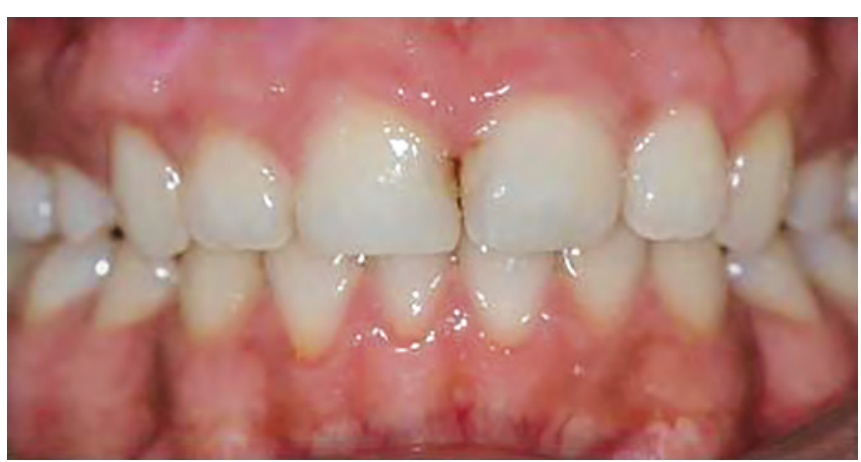

Fig. 1: Preoperative diagnostic photograph, frontal view 


\section{Periodontal Health}

- The probing depth in the area should be within the healthy limits.

- Presence of periodontal pockets or spontaneous bleeding on probing are primary indicators of presence of periodontal disease and treatment should be postponed till these problems are addressed.

- Crown lengthening should only be performed on healthy tissue.

- Tooth mobility and bony defects render cases unfit for the procedure.

- If the crown-root ratio is unfavorable at the end of the procedure, alternative options should be considered.

- Existence of periodontal pockets in multiple areas of the mouth could suggest a predisposition to periodontal disease; therefore, even if the targeted area is healthy, treatment should be postponed till a stable periodontal condition is established or alternative treatment methods should be considered.

\section{Biologic Width}

Biological width is a term coined by Kois. ${ }^{9,24}$ It includes the dimensional sum of the sulcus depth, connective tissue, and epithelial attachment. In healthy tissue the average width is approximately $3 \mathrm{~mm}$ in the facial and lingual aspect and around 3 to $5 \mathrm{~mm}$ in the mesial and distal aspect of any tooth. ${ }^{9,15,23,24}$ To ensure a predictable and stable crown lengthening, it is critical to maintain the biologic width at the end of the procedure. ${ }^{2,9,15,23,24}$

- Kao et $\mathrm{al}^{27}$ stress that "Measuring the zone of attached gingiva determines the type of attached gingivaanatomic crown relationship. Transgingival sounding of the alveolar crest determines its relationship to the gingival crest, the cementoenamel junction (CEJ), and the mucogingival junction. The location of these anatomical landmarks will indicate whether there is gingival excess or normal gingival width and the location of alveolar crest in relationship to the CEJ. The surgical treatments to correct these defects are based on this differential diagnosis."

- Bone sounding is performed before the procedure, under anesthesia, to determine the location of the alveolar crest in relation to the CEJ and the need for osseous resection to preserve the biologic width on all surfaces of the teeth post crown lengthening (Fig. 2). It is performed a second time after the gingival excess has been removed and osseous recontouring is performed as necessary. Dyer suggests bone sounding on adjacent teeth to determine the average biologic width of the patient. He also recommends resecting bone $1 \mathrm{~mm}$ more than the average biologic width. ${ }^{2}$

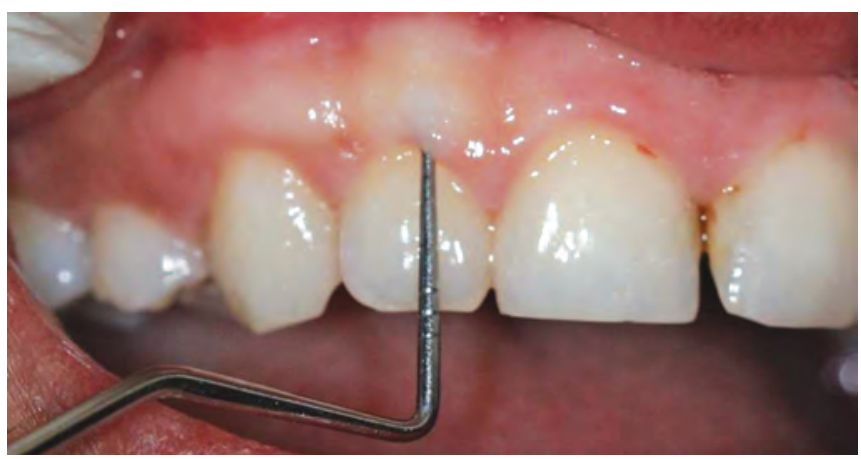

Fig. 2: Transgingival bone sounding

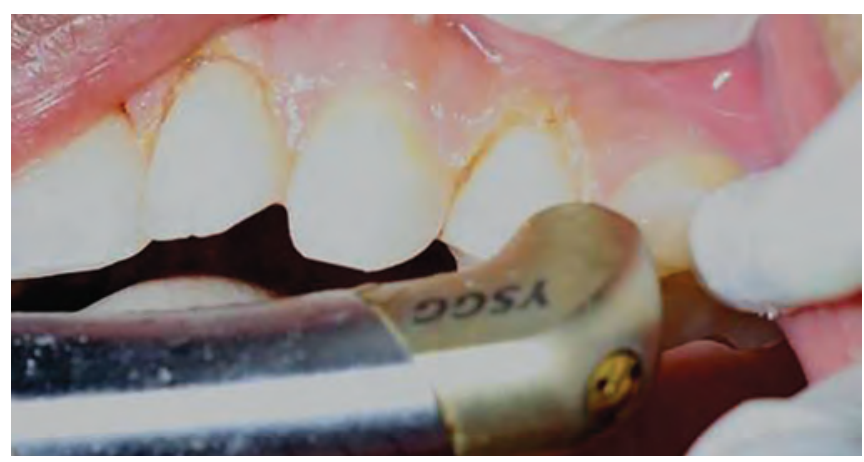

Fig. 3: Removal of excess gingiva with laser at lower settings

\section{Removal of Gingival Excess}

The desired gingival margin is marked in the patient's mouth. The erbium laser is used with lower settings to remove the gingival excess (Fig. 3).

\section{Osseous Recontouring}

Once the final gingival margin has been established and the required osseous recontouring has been determined, the laser is used to create an intrasulcular trough to improve access to the alveolar crest. The desired depth of resection is marked onto the laser tip with the help of a caliper. The laser tip is set at higher settings and kept parallel to the root surface and perpendicular to the alveolar crest ${ }^{9,15,23,24}$ (Fig. 4). van $\mathrm{As}^{28}$ suggests using

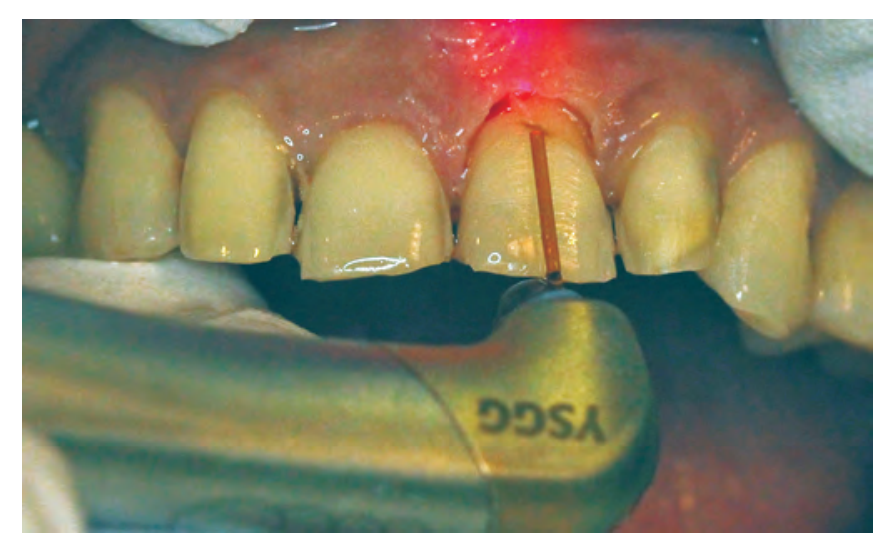

Fig. 4: Osseous recontouring of bone with laser at higher settings. Laser tip is kept as parallel to the tooth structure as possible and the desired depth of cutting is marked on the tip with the help of calipers 
lasers for osseous recontouring only in very localized or minor cases, such as one surface of a tooth. In case of circumferential recontouring or multiple teeth, he recommends use of an open-flap approach for the osseous recontouring. Dyer recommends reflection of the gingival papilla in cases of circumferential bone resection. ${ }^{2}$ Flax reported successful results after closed-flap laser-assisted crown lengthening on multiple anterior teeth. $^{15,23,24}$

\section{Smoothing and Final Shaping of the Marginal Bone}

Most clinicians used a 7/8 Gracey curette to smoothen the resection after the use of the laser. ${ }^{15,23,24,28}$ Dyer $^{2}$ used a slow speed rotary diamond with irrigation to smoothen and shape the marginal bone. Tosun et $\mathrm{al}^{1}$ in their in vitro study on sheep mandible, also used a 7/8 Gracey curette to smoothen the bone surface post recontouring with the laser.

\section{Impressions for the Final Prosthesis}

Impressions for the final prosthesis can be made on the same day as the crown lengthening, unless the case calls for a review of the margins before final impressions (Fig. 5). Flax used a polyvinylsiloxane impression material to take a full arch impression immediately after a closedflap crown lengthening in one of his case reports. ${ }^{24}$ van $\mathrm{As}^{28}$ suggests that impressions can be made in the same appointment if a closed-flap crown lengthening is used to achieve the ideal biologic width for the final restoration.

\section{Maintenance of Oral Hygiene and Post-surgical Care}

In all case reports a vigorous and strict home care regimen was instructed to the patient, which consisted

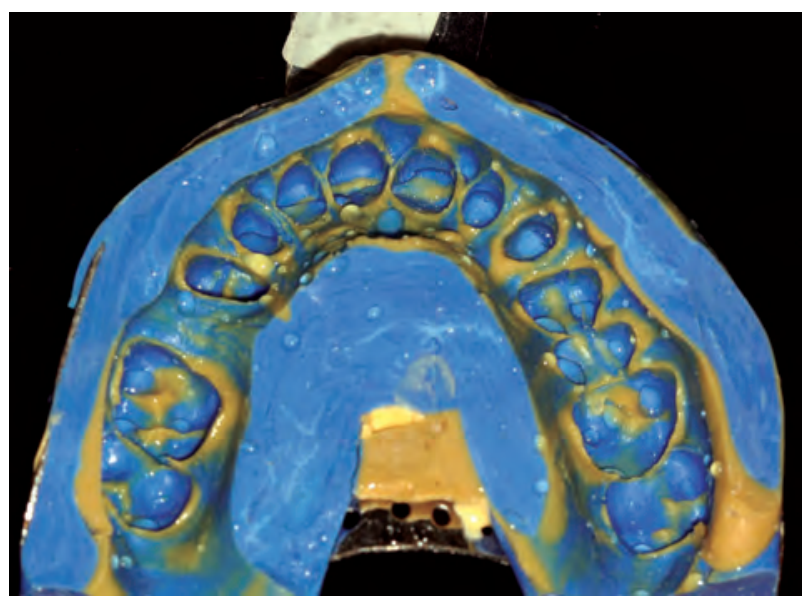

Fig. 5: Polysilicone impression post procedure

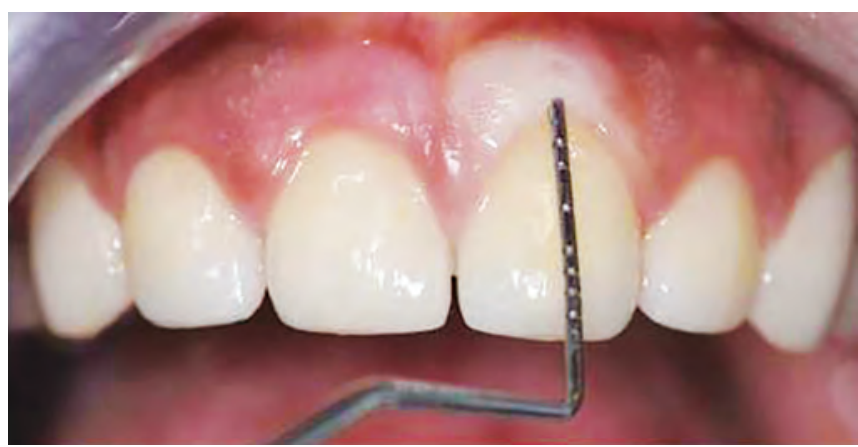

Fig. 6: Follow-up to check healing of soft tissues and reconfirm maintenance of biologic width

Oxyfresh Worldwide, Inc., Spokane, WA 99216;(800):333-7374

of Oxygel ${ }^{*}, 0.12 \%$ chlorhexidine gluconate, and gingival massage. Mild nonsteroidal anti-inflammatory medication was prescribed for pain. ${ }^{2,15,23,24}$ Dyer $^{2}$ sealed the tissues with cyanoacrylate postoperatively. All cases were followed up weekly to monitor the healing $2,15,23,24$ (Fig. 6).

\section{CONCLUSION}

There are numerous case reports that demonstrate laser-assisted closed-flap crown lengthening to be a predictable procedure with satisfactory results. When provided by a clinician with the adequate training in the use of lasers and with appropriate case selection, it can greatly enhance patient satisfaction and reduce chairside time. In some cases impressions can be taken on the same day of the procedure. It also significantly reduces healing time. The procedure is almost pain-free and does not have the same postoperative complications as a traditional crown lengthening, hence greatly increasing the patient acceptance. With the increasing popularity of smile designing, it is a great alternative to the conventional method. Appropriate case selection, maintenance of biologic width, and a strict home-care regime are critical for a successful outcome. When used judiciously, it is a very viable treatment option, which must be considered in every modern dental practice (Figs 7 and 8).

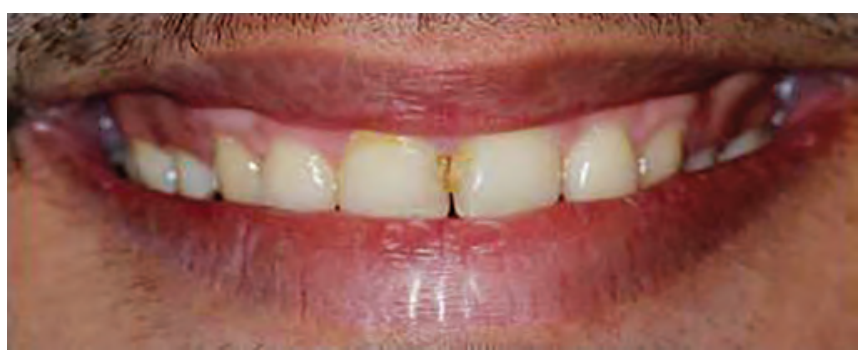

Fig. 7: Preoperative diagnostic photograph 


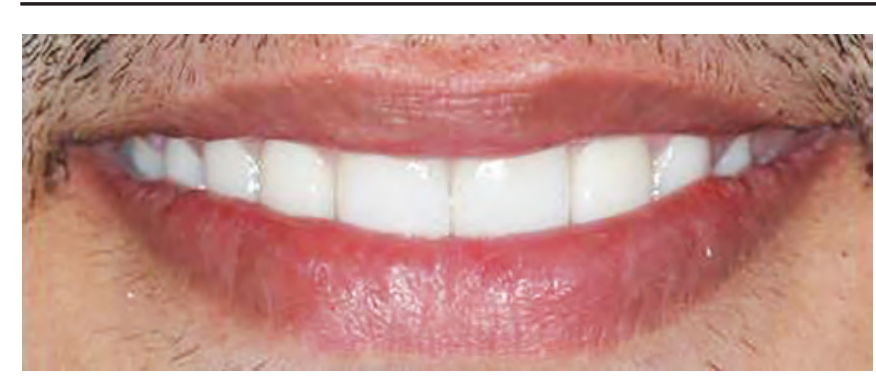

Fig. 8: Postoperative result

\section{REFERENCES}

1. Tosun T, Iaria G, Benedicenti S. Comparison of Er:YAG laser flapless crown lengthening vs. open-flap bur approach in animal studies. J Laser Dent 2012 Jan;20(1):10-15.

2. Dyer BL. Minimally invasive osseous crown-lengthening procedure using an erbium laser: clinical case and procedure report. J Cosmet Dent 2008;23(4):84-91.

3. Kina JR, Dos Santos PH, Kina EF, Suzuki TY, Dos Santos PL. Periodontal and prosthetic biologic considerations to restore biological width in posterior teeth. J Craniofac Surg 2011 Sep;22(5):1913-1916.

4. Miller PD Jr. Regenerative and reconstructive periodontal plastic surgery. Mucogingival surgery. Dent Clin North Am 1988 Apr;32(2):287-306.

5. Feigenbaum N. The challenge of cost restrictions in smile design. Pract Periodontics Aesthet Dent 1991 Sep;3(6):41-44.

6. Hempton TJ, Dominici JT. Contemporary crown-lengthening therapy: a review. J Am Dent Assoc 2010 Jun;141(6): 647-655.

7. Pontoriero R, Carnevale G. Surgical crown lengthening: a 12-month clinical wound healing study. J Periodontol 2001 Jul;72(7):841-848.

8. Deas DE, Moritz AJ, McDonnell HT, Powell CA, Mealey BL. Osseous surgery for crown lengthening: a 6-month clinical study. J Periodontol 2004 Sep;75(9):1288-1294.

9. Kois JC. Altering gingival levels: the restorative connection. Part I: biologic variables. J Esthet Dent 1994 Jan;6(1):3-7.

10. Powell CA, Mealey BL, Deas DE, McDonnell HT, Moritz AJ. Post-surgical infections: prevalence associated with various periodontal surgical procedures. J Periodontol 2005 Mar;76(3): 329-333.

11. Cobb CM. AAP. Lasers in periodontics: a review of the literature. J Periodontol 2006 Apr;77(4):545-564.

12. Mahajan A. Lasers in periodontics - a review. Eur J Dent Med 2011;3(1):1-11.
13. Coluzzi DJ. What laser does your practice need? Advantages, considerations, and practice integration of laser dentistry. Alpha Omegan 2008 Dec;101(4):202-205.

14. Parker S. Verifiable CPD paper: laser-tissue interaction. $\mathrm{Br}$ Dent J 2007 Jan 27;202(2):73-81.

15. Flax HD. Maximizing esthetic transformations using a closed flap Er,Cr:YSGG modality. Compend Contin Educ Dent 2005 Mar;26(3):172-176.

16. van As G. Erbium lasers in dentistry. Dent Clin North Am 2004 Oct;48(4):1017-1059.

17. Freiberg RJ, Cozean C. Pulsed erbium laser ablation of hard dental tissue: the effects of atomized water spray versus water surface film. Lasers in dentistry VIII. Proc SPIE 2002;4610:74-84.

18. Bornstein E, Lomke MA. The safety and effectiveness of dental Er: YAG lasers: a literature review with specific reference to bone. Dent Today 2003 Oct;22(10):129-133.

19. Parker SP, Darbar AA, Featherstone JD, Iaria G, Kesler G, Rechmann P, Swick MD, White JM, Wigdor HA. The use of laser energy for therapeutic ablation of intraoral hard tissues. J Laser Dent 2007;15(2):78-86.

20. de Mello ED, Pagnoncelli RM, Munin E, Filho MS, de Mello GP, Arisawa EA, de Oliveira MG. Comparative histological analysis of bone healing of standardized bone defects performed with the Er:YAG laser and steel burs. Lasers Med Sci 2008;23(3):253-260.

21. Romeo U, Del Vecchio A, Palaia G, Tenore G, Visca P, Maggiore C. Bone damage induced by different cutting instruments - an in vitro study. Braz Dent J 2009;20(2):162-168.

22. Kimura Y, Yu DG, Fujita A, Yamashita A, Murakami Y, Matsumoto K. Effects of erbium, chromium:YSGG laser irradiation on canine mandibular bone. J Periodontol 2001 Sep;72(9):1178-1182.

23. Flax HD. Soft and hard tissue management using lasers in esthetic restoration. Dent Clin North Am 2011 Apr;55(2): 383-402.

24. Flax HD, Radz GM. Closed-flap laser assisted esthetic dentistry using Er:YSGG technology. Compend Contin Educ Dent 2004 Aug;25(8):622-628.

25. Bragger U, Launchenauer D, Lang NP. Surgical lengthening of the clinical crown. J Clin Periodontol 1992 Jan;19(1):58-63.

26. Yung FY. The use of an Er:YAG laser in periodontal surgery. Int Dent (Austr Ed) 2011;6(3):6-19.

27. Kao RT, Dault S, Frangadakis K, Salehieh JJ. Esthetic crown lengthening: appropriate diagnosis for achieving gingival balance. J Calf Dent Assoc 2008 Mar;36(3):187-191.

28. van As G. Osseous recontouring with the Er:YAG laser to obtain ideal biologic width. J Can Dent Assoc 2005;71(1):53-55. 